\title{
PO2-6-31 Poster session
}

\section{PLX-R18- Placenta-derived Mesenchymal-like Stromal Cells are efficacious in reducing lethality in Gastrointestinal Acute Radiation Syndrome (GI-ARS) Mouse Model}

\author{
Yoshiyuki Soeda ${ }^{1}$, Racheli Ofir ${ }^{2}$, Noa Sher ${ }^{2}$, Yoshiyuki Suzuki ${ }^{3}$, Zami Aberman ${ }^{2}$, Akihiro Inano $^{1}$ \\ ${ }^{\prime}$ Medical Research Center/Clinical Research Center, Fukushima Medical University, Fukushima, Japan, ${ }^{2}$ Pluristem \\ Therapeutics Inc., Israel, ${ }^{3}$ Department of Radiation Oncology, Japan
}

[BACKGROUND] PLX-R18 cells are placenta-derived mesenchymal-like stromal cells that have been shown to be efficacious in reducing lethality and alleviating symptoms of hematopoietic subsyndrome of ARS in rodent and primate models. They are also studied in phase I clinical trials for treatment of incomplete hematopoietic recovery after hematopoietic cell transplantation. Here we show that PLX-R18 cells are also effective mitigators of the ARS elicited by exposure to high-dose $\mathrm{x}$-ray irradiation.

[METHODS] To assess their therapeutic potential, PLX-R18 cells $\left(2.0 \times 10^{\wedge} 6\right.$ cells/mouse) were administered to 8 -weekold C57BL6/J male mice intramuscularly, 1 and 5 days following total body irradiation (TBI) at 11 Gy, or partial-body irradiation with $40 \%$ bone marrow sparing (PBI-BM40) at 14 Gy. Body weight and animal survival were monitored, and gastrointestinal tract histology and blood parameters were analyzed.

[RESULTS] In mice exposed to PBI-BM40, rate of survival in mice treated with PLX-R18 cells (87.5\%; $\mathrm{n}=8)$ in 8 and 9 days was higher than with vehicle control $(50.0 \% ; n=8)(p=0.106)$. Mean body weight in mice treated with PLX-R18 cells $(18.2 \pm 0.3 \mathrm{~g} ; \mathrm{n}=8)$ was significantly larger than with vehicle control $(16.9 \pm 0.3 \mathrm{~g} ; \mathrm{n}=8)$ in 6 days after PBI-BM40 $(\mathrm{p}=0.0037)$. Significant reduction of level of white blood cells was observed in mice exposed by PBI-BM40 $(2.9 \pm 0.3 \mathrm{x}$ $10^{\wedge} 3$ cells $\left./ \mu \mathrm{l} ; \mathrm{n}=4\right)$ at 14 days, compared with no irradiation $\left(10.4 \pm 1.1 \times 10^{\wedge} 3\right.$ cells/ $\left.\mu \mathrm{l} ; \mathrm{n}=3\right)$. Administration of PLX-R18 cells inhibited the reduction of white blood cells at 14 days $\left(5.5 \pm 1.8 \times 10^{\wedge} 3\right.$ cells $\left./ \mu l ; n=4\right)(p=0.1668)$. The administration of PLX-R18 cells was no effect in mice exposed to TBI.

[CONCLUSIONS] The current data suggest that PLX-R18 improves symptoms of GI-ARS. Thus, PLX-R18 cells may be novel agent for treatment of GI-ARS. 